\title{
FACILE MICROWAVE -ASSISTED SYNTHESIS OF CASEIN DERIVED CARBON NANODOTS
}

\author{
${ }^{1}$ R. Blessy PRICILLA, ${ }^{1}$ David ŠKODA, ${ }^{1}$ Pavel URBÁNEK, ${ }^{1}$ Michal URBÁNEK, ${ }^{1}$ Ivo KUŘITKA* \\ ${ }^{1}$ Centre of Polymer Systems, Tomas Bata University in Zlín, Czech Republic, EU, kuritka@utb.cz
}

https://doi.org/10.37904/nanocon.2020.3681

\begin{abstract}
Belonging to the carbon family, yet standing apart, carbon nanodots are materials with excellent properties. Among them, they are well known for their attractive optical properties. The insight into this outstanding strength has resulted in the discovery of unique design of materials. These nanodots can be prepared via various methods to obtain a good optical response. In our research, we synthesized them using a microwave reactor, which is simple, fast and productive. As a carbon source casein, a low-cost precursor was used. Since this is a protein composed of amino acids, no additional passivation was required. Polyvinylpyrrolidone was used as a stabilizer for the nanodots. The synthesis was carried out at $200{ }^{\circ} \mathrm{C}$ for 30 minutes. The color change of the resulting solution to orange brown indicates the formation of carbon nanodots. These nanodots were filtered and dialyzed to be used for further characterizations. The carbon nanodots were spherical with the average size of about $9.7 \mathrm{~nm}$. They showed a strong blue emission in the visible region with an appreciable quantum yield. One of the important characteristics of this method is the availability of reasonably good product yield. The prepared carbon nanodots have potential applications in the field of electrochemistry, optoelectronics and biological imaging.
\end{abstract}

Keywords: Carbon nanodots, casein, microwave reactor, Polyvinylpyrrolidone

\section{INTRODUCTION}

In the recent decade, carbon nanodots (CNDs) have emerged as excellent luminescent materials. Since these materials manifest extraordinary merits, they are the hot topic of research studies. CNDs are materials with dimensions less than $10 \mathrm{~nm}$. They were discovered in 2004 during the purification of single-walled carbon nanotubes [1]. Because of their alluring properties, CNDs are extensively used in applications like bioimaging [2], light emitting diodes [3] and sensing of metal ions [4]. Moreover, researchers all around the world have discovered different methods for synthesis such as hydrothermal [5], microwave irradiation [6] and laser ablation [7] The structure of CNDs contains a mixture of $\mathrm{sp}^{2}$ and $\mathrm{sp}^{3}$ hybridized carbon atoms with an amorphous core. To enhance the optical properties, their surface is usually passivated with various functional groups or heteroatoms. Furthermore, depending on the surface structure, hydrophilic [8], hydrophobic [9] and amphiphilic [10] CNDs can be obtained.

Amongst all the properties, the optical properties have been widely investigated. The core and surface states play a crucial role in the emission. Recently, different kinds of carbon precursors have been used to obtain better photoluminescence (PL) response [11,12]. Even though the mechanism of PL emission is still under debate, the three most important mechanisms include quantum confinement, surface state and molecular fluorophore [13]. CNDs usually follow the trend of excitation dependent PL spectra with strong emission in the blue region, whose intensity decreases with the red shift. This red shift in the PL spectra is observed due to high surface oxidation [14].

To further investigate the optical property, fluorescence lifetime decay studies are carried out, which helps in understanding the potential applications of CNDs. Multi-exponential decay of these studies is considered as a 
fingerprint of heterogeneity which is obtained from dot-to-dot differences in excited-state lifetimes [15]. Another important optical property is the fluorescence quantum yield. One group of researchers synthesized CNDs using citric acid and urea and studied the factors affecting the quantum yield. They discovered that high temperature and longer reaction time lead to a decrease in the quantum yield [16]. Achieving high fluorescence quantum yield with a good product yield has always been a challenge.

Even though CNDs have been synthesized from different precursors, their chemical, structural and optical properties have not been clearly understood yet. In our work, we synthesized CNDs from a protein named casein. Since casein is rich in amino acids, doping was avoided. The structural, chemical and optical properties of the synthesized material were studied using transmission electron microscope, fourier transform infrared spectroscopy, UV-Vis spectroscopy and photoluminescence spectroscopy.

\section{EXPERIMENTAL}

\subsection{Materials required}

MPC 85 Micellar Casein was purchased from a local seller in the Czech Republic. Polyvinylpyrrolidone (PVP) was bought from Sigma Aldrich. Solvents like ethylene glycol and isopropanol were procured from PENTA, Czech Republic. All reagents were used without any further purification.

\subsection{Synthesis of casein based carbon nanodots}

The synthesis of casein based carbon nanodots (CNDs) was carried out using a microwave reactor. In the typical synthesis, $0.1 \mathrm{~g}$ of casein and $0.2 \mathrm{~g}$ of PVP were taken in two separate beakers and dissolved in $20 \mathrm{ml}$ of ethylene glycol separately using a sonication probe. Then, the two solutions were mixed and poured in a teflon lined container to be kept in the microwave reactor. This reaction mixture was maintained at $200^{\circ} \mathrm{C}$ for 30 minutes with $100 \%(600 \mathrm{~W})$ power. After 30 minutes an orange-brown solution was obtained. This solution of carbon nanodots was filtered using a $0.22 \mu \mathrm{m}$ membrane and dialyzed against water using a dialysis bag $(3.5 \mathrm{KD})$ for two days to remove the excess of PVP. The resulting solution was freeze dried and the final product $(40 \mathrm{mg})$ was obtained.

\subsection{CNDs characterization}

The synthesized CNDs were characterized using various characterization techniques. The Ultraviolet-Visible (UV-Vis) absorption studies were carried out on Perkin-Elmer Lambda 1050 spectrometer. The photoluminescence (PL) emission spectra was recorded on FLS920, Edinburgh Instruments (excitation laser $332.2 \mathrm{~nm}$, Xe lamp excitation $515 \mathrm{~nm}$ ). The Fourier Transform Infrared (FTIR) spectra were obtained from Thermo Scientific Nicolet 6700 spectrometer utilizing the ATR method with the diamond crystal (4000$400 \mathrm{~cm}^{-1}$, resolution $2 \mathrm{~cm}^{-1}, 64$ scans). Transmission Electron Microscope (TEM) studies were carried out on the JEOL JEM 2100 microscope operated at $300 \mathrm{kV}$ (LaB 6 cathode, point resolution $2.3 \AA$ equipped with OLYMPUS SYS TENGRA camera $(2048 \times 2048$ pixels $))$. The particle analysis was carried out using Image $\mathrm{J}$ software.

\section{RESULTS AND DISCUSSIONS}

The morphology and the size of the synthesized CNDs was confirmed through TEM characterization. The TEM image is shown in Figure 1. As can be seen, the particles are randomly distributed with a spherical shape and of different sizes. The average particle size of the CNDs was found to be around $9.7 \mathrm{~nm}$. 


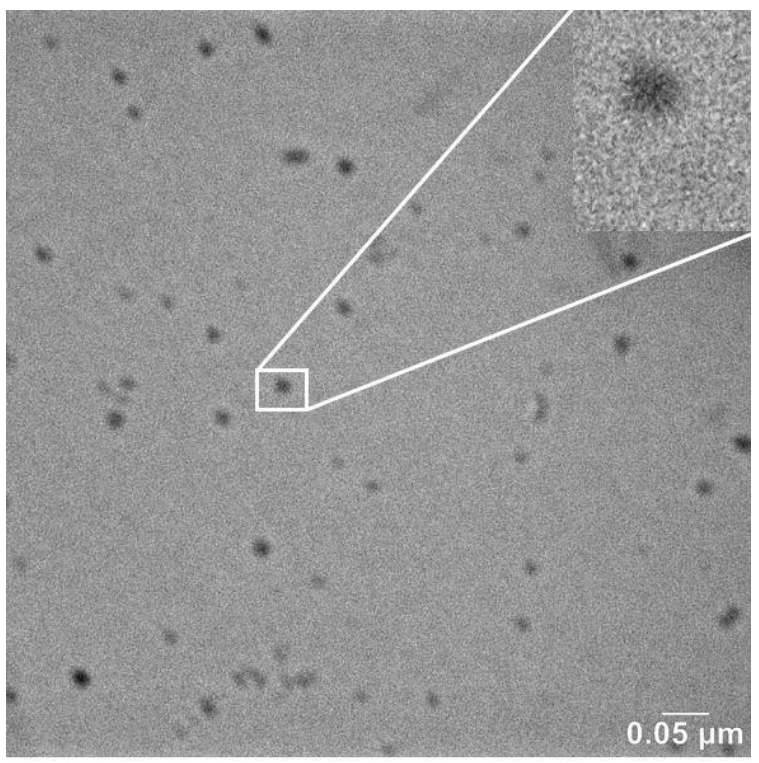

Figure 1 TEM image of CNDs

Figure 2 provides the FTIR spectrum of the CNDs. As shown, the spectrum indicates the presence of various functional groups. The peak at $3357 \mathrm{~cm}^{-1}$ shows $\mathrm{O}-\mathrm{H}$ and $\mathrm{N}-\mathrm{H}$ stretching vibrations. Characteristic casein peaks were observed at $2920 \mathrm{~cm}^{-1}$ and $1850 \mathrm{~cm}^{-1}$ due to the appearance of symmetric and asymmetric stretching of $\mathrm{CH}_{2}$ [17]. The existence of $\mathrm{C}=\mathrm{O}$ stretching vibrations can be found at $1656 \mathrm{~cm}^{-1}, \mathrm{O}-\mathrm{H}$ bending vibrations are seen at $1423 \mathrm{~cm}^{-1}$. The peaks present at $1288 \mathrm{~cm}^{-1}$ and $1043 \mathrm{~cm}^{-1}$ indicate $\mathrm{C}-\mathrm{N}$ stretching and C-O stretching, respectively.

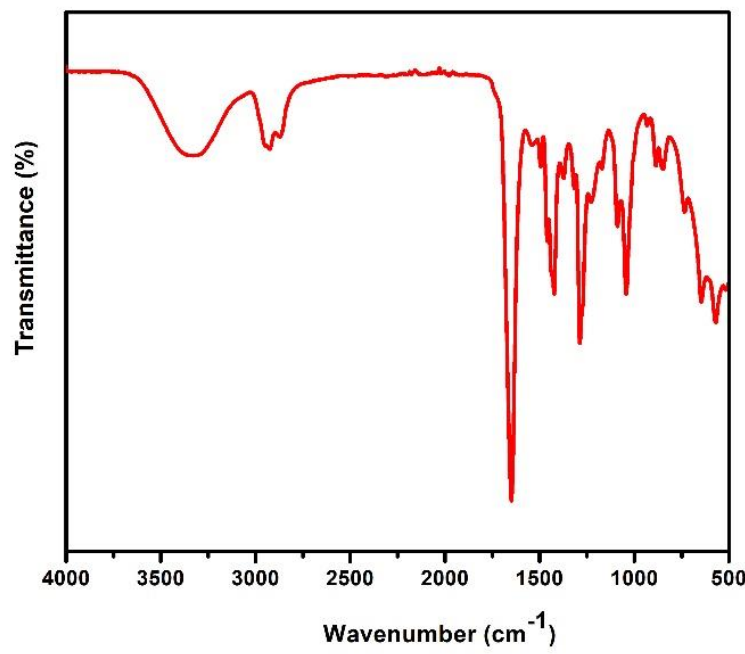

Figure 2 FTIR spectra of CNDs

The optical studies help in understanding the electronic transitions happening in CNDs. Therefore, we have investigated the absorption and emission spectra. When the CNDs were illuminated with a UV lamp of wavelength $365 \mathrm{~nm}$, a blue color solution was observed. Figure 3 (a) shows the UV spectra of Casein based carbon nanodots. As can be seen, a peak is observed at $278 \mathrm{~nm}$. This peak is due to the $\pi-\pi^{*}$ transition of the aromatic $\mathrm{C}=\mathrm{C}$ bond [18]. The $\mathrm{PL}$ emission spectra of the CNDs excited from $320-420 \mathrm{~nm}$ is shown in Figure 3 (b). As revealed by the graph, an initial increase in the peak intensity is observed, followed by a 
gradual decrease.The presence of surface defects due to a high level of surface oxidation causes emission to shift to longer wavelengths [19]. When the CNDs were excited at $350 \mathrm{~nm}$, the highest peak was obtained at $427 \mathrm{~nm}$, which appears to be in the region of blue emission. The polydispersity of the sample can be one of the factors for the formation of excitation dependent emission spectra.
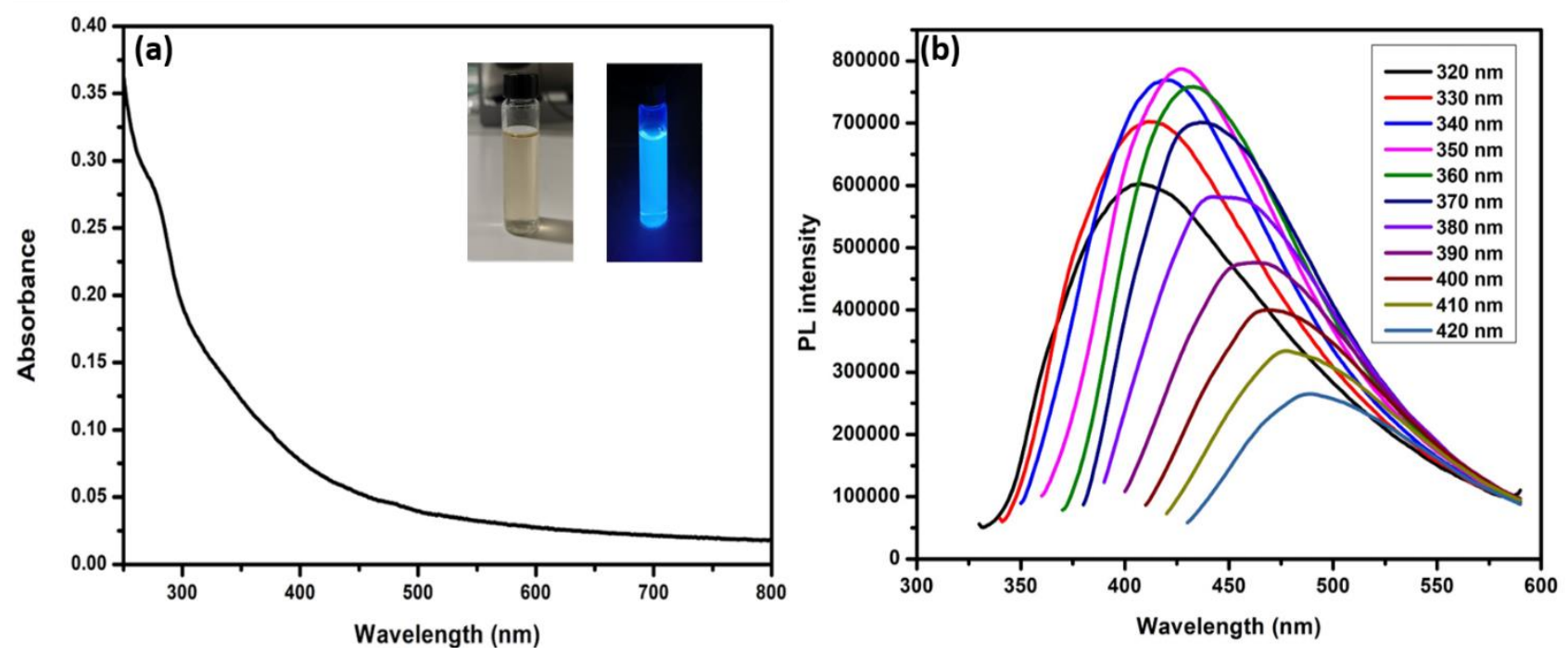

Figure 3 a) UV absorption spectra of CNDs b) PL emission spectra of CNDs

The quantum yield of the CNDs with water as a reference was found to be $4 \%$, which is comparable with those reported in the literature $[17,20]$.

\section{CONCLUSION}

In summary, the study has reported a successful synthesis of CNDs using a simple and easy approach. The resulting CNDs are spherical in shape, they exhibit excitation dependent photoluminescence spectra with a red shift, indicating the heterogeneity of the sample. A strong blue color emission indicates the typical characteristic of the material. Compared to all the other methods, this technique is less time consuming and easily reproducible with a good yield. The bare casein CNDs show considerably less quantum yield than expected, hence it is concluded that in the next step, passivation is necessary to obtain an increase in this property. Passivating these CNDs with various functional groups or dopants can lead to their application in numerous arenas like biomarkers, optoelectronics, drug delivery and photosensitizer.

\section{ACKNOWLEDGEMENTS}

\section{The authors gratefully acknowledge the financial support of the Ministry of Education, Youth and Sports of the Czech Republic Program- DKRVO (RP/CPS/2020/006).}

\section{REFERENCES}

[1] XU, X., RAY, R., GU, Y., PLOEHN, H.J., GEARHEART, L., RAKER, K., SCRIVENS W.A. Electrophoretic analysis and purification of fluorescet single-walled carbon nanotube fragments. J Am Chem Soc. 2004, vol. 123, no. 40, pp. $12736-12737$.

[2] ZHU, S., MENG, Q., WANG, L., ZHANG, J., SONG, Y., JIN, H., ZHANG, K., SUN, H., WANG, H., YANG, B. Highly Photoluminescent Carbon dots for multicolor patterning, sensors and bioimaging. Angew. Chem. Int. Ed. 2013, vol 52, no. 14, pp. 3953-3957.

[3] MIRASOL, S.P., FERRERO, E.M., PALOMARES, E. Direct white light emission from carbon nanodots (C-dots) in solution processed light emitting diodes. Nanoscale. 2019, vol 11, no. 23, pp. 11315-11321. 
[4] SAI, L., CHEN, J., CHANG, Q., SHI, W., CHENA, Q., HUANG, L. Protein-derived carbon nanodots with an ethylenediamine-modulated structure as sensitive fluorescent probes for $\mathrm{Cu}_{2}{ }^{+}$detection. RSC Adv. 2017, vol 7, no. 27 , pp. $16608-16615$.

[5] KUMAR, V.B., SHEINBERGER, J., PORAT, Z., TAL, Y.S., GEDANKEN, A. A hydrothermal reaction of an aqueous solution of BSA yields highly fluorescent $\mathrm{N}$ doped $\mathrm{C}$-dots used for imaging of live mammalian cells. $J$ Mater Chem B. 2016, vol 4, no. 17, pp. 2913-2920.

[6] MEDEIROS, T.V., MANIOUDAKIS, J., NOUN, F., MACAIRAN, J.R., VICTORIA, F., NACCACHE R. Microwaveassisted synthesis of carbon dots and their applications. J. Mater. Chem. C. 2019, vol 7, no. 24, pp. 7175-7195.

[7] REYES, D., CAMACHO, M., CAMACHO, M., MAYORGA, M., WEATHERS, D., SALAMO, G., WANG, Z., NEOGI, A. Laser Ablated Carbon Nanodots For Light Emission. Nanoscale Res Lett. 2016, vol 11, p. 424.

[8] YANG, Y.Z., XIAO, N., LIU, S.G., HAN, L., LI, N.B., LUO, H.Q. pH-induced aggregation of hydrophilic carbon dots for fluorescence detection of acidic amino acid and intracellular $\mathrm{pH}$ imaging. Materials Science and Engineering: C. 2020, vol 108, p. 110401.

[9] YANG, H., LIU, Y., GUO, Z., LEI, B., ZHUANG, J., ZHANG, X., LIU, Z., HU, C. Hydrophobic carbon dots with blue dispersed emission and red aggregation-induced emission. Nat Commun. 2019, vol 10, p. 1789.

[10] WANG, H.J., HE, X., LUO, T.Y., ZHANG, J., LIU, Y.H., YU, X.Q. Amphiphilic carbon dots as Versatile vectors for nucleic acid and drug delivery. Nanoscale. 2017, vol 9, no. 18, pp. 5935-5947.

[11] BAJPAI, S. K., D'SOUZA, A., SUHAIL, B. Blue light-emitting carbon dots (CDs) from a milk protein and their interaction with Spinacia oleracea leaf cells. International Nano Letters. 2019, vol 9, pp. 203-212.

[12] JIANG, K., SUN, S., ZHANG, L., LU, Y., WU, A., CAI, C., LIN, H. Red, Green, and Blue Luminescence by Carbon Dots: Full-Color Emission Tuning and Multicolor Cellular Imaging. Angew. Chem. 2015, vol 54, no. 18, pp. 53605363.

[13] CAYUELA, A., SORIANO, M.L., CARRILLO-CARRIO, C., VALCARCEL, M. Semiconductor and carbon-based fluorescent nanodots: the need for consistency. Chem. Commun. 2016, vol 52, no. 7, pp. 1311-1326.

[14] DING, H., YU, S.B., WEI, J.S., XIONG, H.M. Full-Color Light-Emitting Carbon Dots With a Surface-StateControlled Luminescence Mechanism. ACS Nano. 2015, vol 10, no. 1, pp. 484-491.

[15] GHOSH, S., CHIZHIK, A.M., KAREDLA, N., DEKALIUK, M.O., GREGOR, I., SCHUHMANN, H., SEIBT, M., BODENSIEK, K., SCHAAP, I.A.T., SCHULZ, O. Photoluminescence of Carbon Nanodots: Dipole Emission Centers and Electron-Phonon Coupling. Nano Lett. 2014, vol 14. no. 10, pp. 5656-5661.

[16] WANG, W., WANG, B., EMBRECHTS, H., DAMM, C., CADRANEL, STRAUSS, V., DISTASO, M., HINTERBERGER, V., GULDI, D.M., PEUKERT, W. Shedding light on the effective fluorophore structure of high fluorescence quantum yield carbon nanodots. RSC Adv. 2017, vol 7, no. 40, pp. 24771- 24780.

[17] SIROČIĆ, A., KREHULA, LJ.K., KATANČIĆ, Z., MURGIĆB, Z.H. Characterization of Casein Fractions Comparison of Commercial Casein and Casein Extracted from Cow's Milk. Chem. Biochem. Eng. Q. 2016, vol 30, no. 4, pp. 501- 509.

[18] ZHU, C., ZHAI, J., DONG, S. Bifunctional fluorescent carbon nanodots: green synthesis via soy milk and application as metal-free electrocatalysts for oxygen reduction. Chem. Commun. 2012, vol 48, no. 75, pp 93679369.

[19] ZHU, S., SONG, Y., ZHAO, X., SHAO, J., ZHANG, J., YANG, B. The photoluminescence mechanism in carbon dots (graphene quantum dots, carbon nanodots, and polymer dots): Current state and future perspective. Nano Research. 2015, vol 8, pp. 355-381.

[20] WANG, N., WANG, Y., GUO, T., YANG, T., CHEN, M., WANG, J. Green preparation of carbon dots with papaya as carbon source for effective fluorescent sensing of Iron (III) and Escherichia coli. Biosensors and Bioelectronics. 2016, vol 85, pp. 68-75. 